\title{
Results of Balloon Valvuloplasty in the Treatment of Congenital Valvar Pulmonary Stenosis in Children
}

\author{
DANIEL A. KVESELIS, MD, ALBERT P. ROCCHINI, MD, A. REBECCA SNIDER, MD, \\ AMNON ROSENTHAL, MD, DENNIS C. CROWLEY, MD, and MACDONALD DICK $\|, M D$
}

\begin{abstract}
Transluminal balloon valvuloplasty was used in the treatment of congenital valvar pulmonary stenosis in 19 children, aged 5 months to 18 years. The right ventricular (RV) systolic pressure and RV outflow tract gradient decreased significantly immediately after the procedure ( $95 \pm 29$ vs $59 \pm 14 \mathrm{~mm} \mathrm{Hg}$, p $<0.01$, and $78 \pm 27$ vs $38 \pm 13 \mathrm{~mm} \mathrm{Hg}, \mathrm{p}<0.01$ ). Seven of these patients were evaluated at cardiac catheterization 1 year after balloon valvuloplasty. No significant change occurred in RV systolic pressure or RV outflow tract gradient at follow-up evaluation compared with measurements immedi-
\end{abstract}

ately after balloon valvuloplasty $(60 \pm 5 \mathrm{~mm} \mathrm{Hg}$ vs $56 \pm 12 \mathrm{~mm} \mathrm{Hg}$ and $39 \pm 5 \mathrm{vs} 38 \pm 10 \mathrm{~mm} \mathrm{Hg}$ ). In addition, follow-up evaluation was performed using noninvasive methods and included electrocardiography $(n=13)$, vectorcardiography $(n=11)$ and Doppler echocardiography $(n=11)$ Doppler echocardiography in 11 patients $15 \pm 9$ months after balloon valvuloplasty showed a continued beneficial effect with a mild further decrease in RV outflow tract gradient. Thus, balloon valvuloplasty is effective in the relief of pulmonary stenosis.

(Am J Cardiol 1985;56:527-532)
Transluminal balloon pulmonary valvuloplasty significantly reduces right ventricular (RV) pressure and RV outflow tract gradient immediately after the procedure. ${ }^{1-5} \mathrm{Kan}$ et $\mathrm{al}^{6,7}$ recently reported their experience with balloon valvuloplasty, including the long-term hemodynamic consequences in 11 patients. The present report is a description of our experience immcdiately after balloon valvuloplasty and at follow-up evaluation with special emphasis on the usefulness of electrocardiography, vectorcardiography and Doppler echocardiography in the assessment of residual obstruction.

\section{Methods}

Patient group: From July 1982 to November 1984, 19 children, aged 0.4 to 17.5 years (mean 4.5), underwent transluminal balloon valvuloplasty for congenital valvar pulmonary stenosis (PS). On examination, 17 of 19 patients had a grade 4 to $5 / 6$ systolic ejection murmur in the left upper sternal border. Only patient 16 had a murmur consistent with pulmonary regurgitation. RV hypertrophy was present on the electrocardiogram. Significant extracardiac disease delayed earlier surgical repair of severe PS in 2 patients. Patient 4 had steroid-dependent nephrotic syndrome and patient 6 had Von Willebrand's disease. In addition, patients 2, 5, 8 and 18 had Noonan's syndrome and patients 6 and 8 had a small ventricular septal defect. Before cardiac catheterization, balloon valvuloplasty was described to the patients and families as an alternative to surgical correction.

From the Department of Pediatrics and Communicable Diseases, Division of Pediatric Cardiology, C.S. Mott Children's Hospital, University of Michigan, Ann Arbor, Michigan. Manuscript received February 11, 1985; revised manuscript received May 7, 1985, accepted May 8 , 1985.

Address for reprints: Daniel A. Kveselis, MD, Pediatric Cardiology, C.S. Mott Children's Hospital, F1123, Box 66, Ann Arbor, Michigan 48109 .
The first 7 patients underwent hemodynamic evaluation at a mean of 1 year after balloon valvuloplasty. Patients were also followed with noninvasive techniques (electrocardiogram, vectorcardiogram and Doppler echocardiogram).

Hemodynamic studies: Cardiac catheterization was performed in all patients premedicated with morphine sulfate $(0.1 \mathrm{mg} / \mathrm{kg}$ body weight, maximal $5 \mathrm{mg}$ intramuscularly) and diphenhydramine $(1 \mathrm{mg} / \mathrm{kg}$ body weight, maximal $50 \mathrm{mg}$ orally). Two venous catheters were placed percutaneously in the right femoral vein and 1 arterial catheter in the right femoral artery. After placement of the catheters, all patients were given heparin $(100 \mathrm{U} / \mathrm{kg}$, maximal $2,000 \mathrm{U}$ intravenously). Right and left heart hemodynamic data were obtained before and after (15 minutes or longer) valvuloplasty, including: simultaneous pulmonary artery, RV and aortic pressures; pulmonary blood flow (using the thermodilution technique in 16 of 19 patients and the Fick principle in 3 of 16 patients); heart rate; and calculation of pulmonary valve area using the formula of Gorlin and Gorlin.

Technique of balloon valvuloplasty: The technique of balloon valvuloplasty has remained unchanged since our earlier report, although we have made several modifications. ${ }^{4}$ The size of the balloon angioplasty catheter (Meditech) was selected to slightly exceed ( 1 to $2 \mathrm{~mm}$ ) the pulmonary valve anulus as estimated either echocardiographically or angiographically. Dilation was performed using 2 angioplasty catheters in patients 17 and 19 because of the large diameter of the pulmonary anulus.

Doppler echocardiography: Examinations were performed in 6 patients during cardiac catheterization while obtaining simultaneous hemodynamic data before and after balloon valvuloplasty. Ultrasonic examination was performed without knowledge of the hemodynamic data.

An Advanced Technology Laboratories Mark 600 ultrasound system with a $2.25-\mathrm{MHz}$ pulsed Doppler transducer and a 2.0-MHz continuous-wave Doppler transducer was used. Examination began with 2-dimensional imaging of the main pulmonary artery from the parasternal short-axis view. Pulsed 


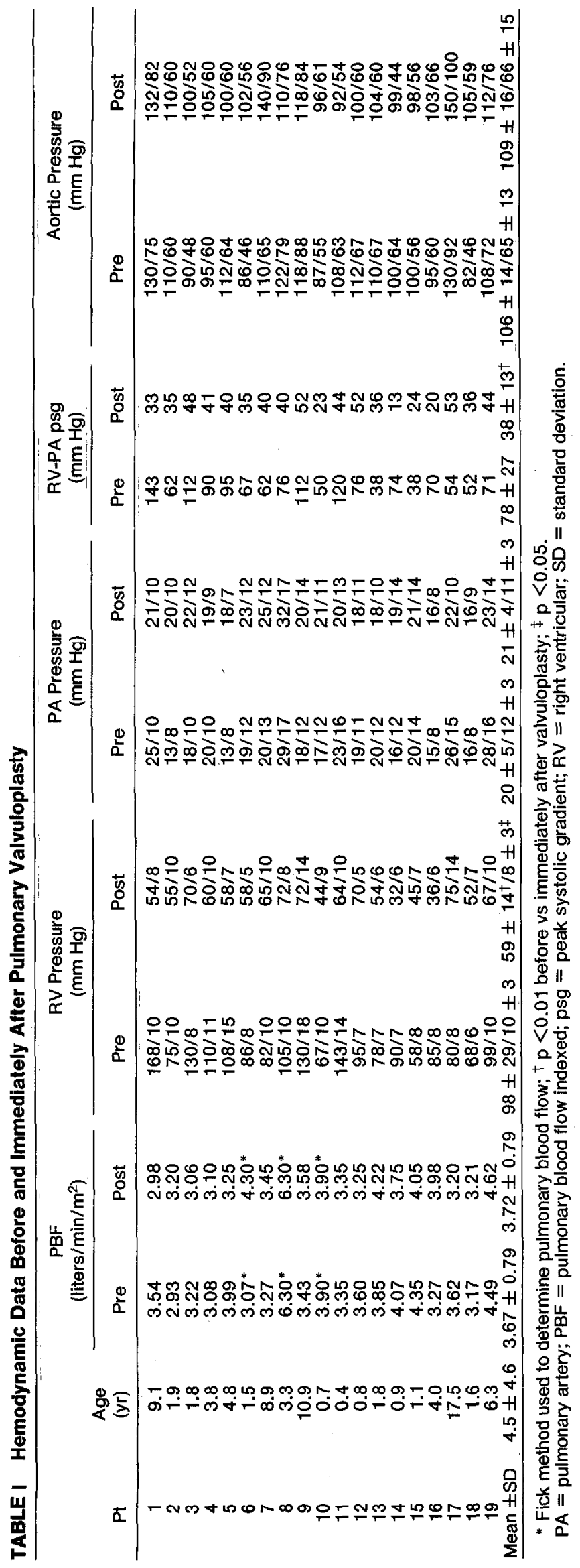

and continuous-wave Doppler interrogation of the main pulmonary artery was done until a maximal velocity was recorded. Doppler examination of the RV outflow tract was done to diagnose pulmonary regurgitation.

The instrument calculated velocity from the frequency shift based on the Doppler equation. ${ }^{8}$ Peak velocities were measured from the Doppler spectral display. The peak systolic velocities from 3 to 4 consecutive beats were averaged and converted to transvalvular gradient using the simplified Bernoulli equation, ${ }^{8} \mathrm{Grad}=4 \mathrm{~V}^{2}$, where $\mathrm{Grad}=$ valvular gradient in $\mathrm{mm} \mathrm{Hg}$ and $\mathrm{V}=$ peak Doppler velocity in meters per second. The Doppler transvalvular gradients were compared to simultaneously recorded peak-to-peak and peak instantaneous RV to pulmonary artery gradients.

Noninvasive evaluation: Evaluation before valvuloplasty and at follow-up was carried out in 13 patients with 12-lead electrocardiograms at rest and in 11 patients with Frank lead vectorcardiograms. Doppler echocardiography was also performed in the resting state in 11 patients at follow-up evaluation.

Statistical analysis: Data are presented as mean \pm standard deviation. Comparisons were made using the Student
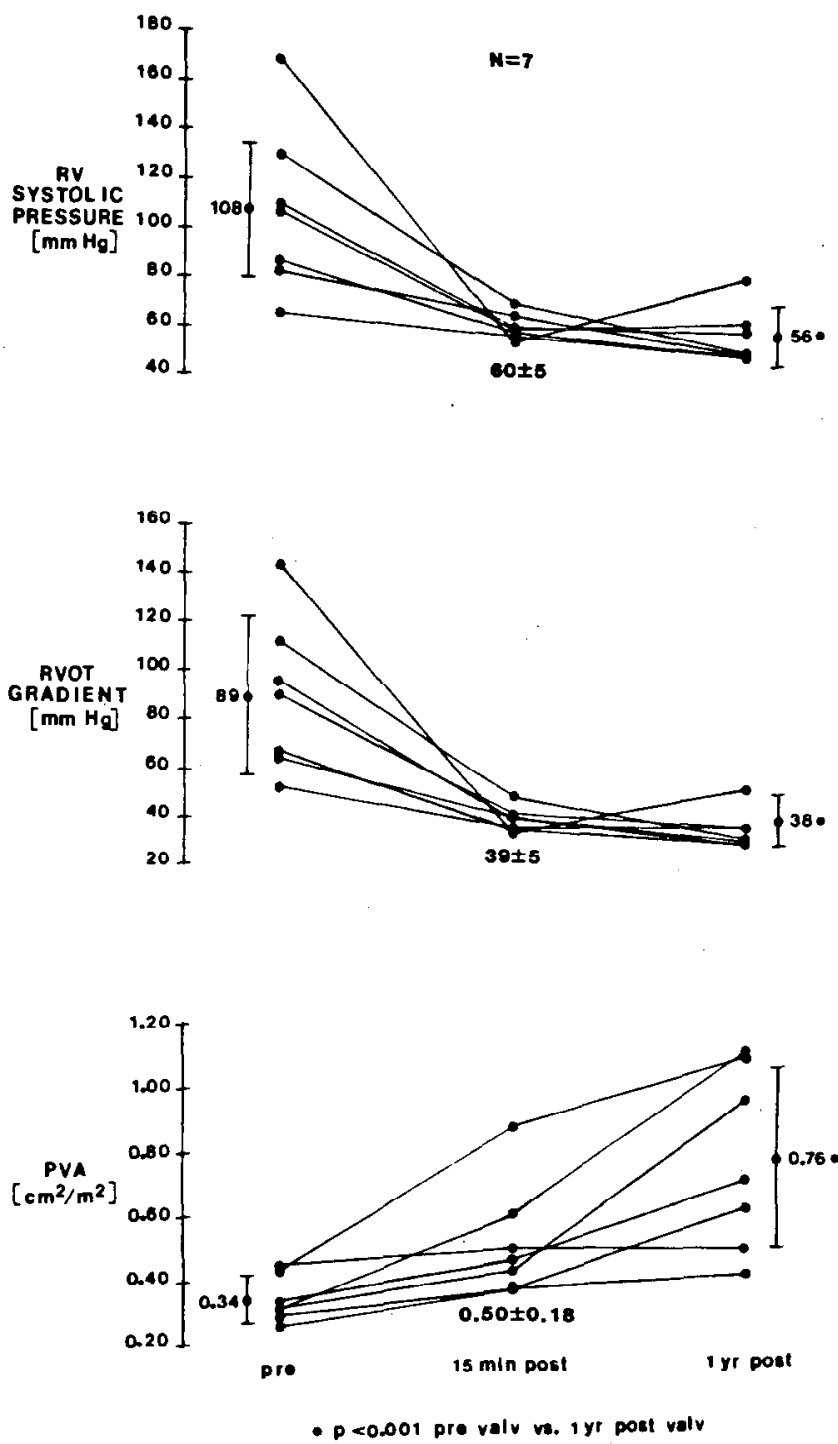

FIGURE 1. Right ventricular (RV) systolic pressure, RV outflow tract (RVOT) gradient and pulmonary valve area index (PVA) in patients 1 to 7 before (pre), immediately after ( $15 \mathrm{~min}$ post) and 1 year after ( 1 yr post) balloon pulmonary valvuloplasty. Results were obtained at cardiac catheterization and are mean \pm standard deviation. 
TABLE II Hemodynamic Data at Follow-Up Evaluation

\begin{tabular}{|c|c|c|c|c|c|c|c|}
\hline \multirow[b]{2}{*}{$P t$} & \multirow[b]{2}{*}{$\begin{array}{c}\text { Follow-Up } \\
(\mathrm{mo})\end{array}$} & \multirow[b]{2}{*}{$\begin{array}{c}\text { PBF } \\
\text { (liters } / \mathrm{min} / \mathrm{m}^{2} \text { ) }\end{array}$} & \multicolumn{4}{|c|}{ Pressure $(\mathrm{mm} \mathrm{Hg})$} & \multirow[b]{2}{*}{$\begin{array}{c}\text { PVA } \\
\left(\mathrm{cm}^{2} / \mathrm{m}^{2}\right)\end{array}$} \\
\hline & & & RV & PA & $\begin{array}{c}\text { RV-PA } \\
\text { psg }\end{array}$ & $\mathrm{AO}$ & \\
\hline $\begin{array}{c}1 \\
2 \\
3 \\
4 \\
5 \\
6 \\
7 \\
\text { Mean } \pm \mathrm{SD}\end{array}$ & $\begin{array}{c}9 \\
13 \\
11 \\
12 \\
12 \\
12 \\
12 \\
11.6 \pm 1.3\end{array}$ & $\begin{array}{c}3.26 \\
2.98 \\
3.25 \\
3.45 \\
3.95 \\
6.83^{*} \\
4.05 \\
3.84 \pm 1.20\end{array}$ & $\begin{array}{l}80 / 10 \\
48 / 4 \\
50 / 7 \\
58 / 6 \\
64 / 6 \\
55 / 7 \\
54 / 5 \\
56 \pm 12 / 7 \pm 2\end{array}$ & $\begin{array}{c}28 / 12 \\
12 / 8 \\
19 / 10 \\
22 / 10 \\
32 / 9 \\
22 / 11 \\
20 / 10 \\
22 \pm 6 / 10 \pm 2\end{array}$ & $\begin{array}{c}52 \\
36 \\
31 \\
36 \\
32 \\
33 \\
34 \\
38 \pm 10\end{array}$ & $\begin{array}{c}138 / 90 \\
104 / 70 \\
102 / 50 \\
86 / 50 \\
108 / 60 \\
94 / 44 \\
110 / 62 \\
106 \pm 16 / 62 \pm 15\end{array}$ & $\begin{array}{c}0.40 \\
0.46 \\
0.62 \\
0.95 \\
0.70 \\
1.10 \\
1.08 \\
0.76 \pm 0.30\end{array}$ \\
\hline
\end{tabular}

$* \mathrm{Qp} / \mathrm{Qs}=1.3$

$\mathrm{AO}=$ aortic: $\mathrm{PVA}=$ pulmonary valve area; other abbreviations as in Table $\mathrm{I}$.

$t$ test for paired data for cardiac catheterization results. Correlation coefficients for linear regression were calculated by comparison of the Doppler-predicted gradients with the actual gradients obtained during cardiac catheterization.

\section{Results}

Early hemodynamic evaluation: Before valvuloplasty, 18 of 19 patients had moderate to severe (at least $50 \mathrm{~mm} \mathrm{Hg}$ systolic gradient) PS (Table I), with an RV outflow tract gradient of $78 \pm 27 \mathrm{~mm} \mathrm{Hg}$. The RV outflow tract gradient decreased immediately after balloon valvuloplasty ( $38 \pm 13 \mathrm{~mm} \mathrm{Hg}, \mathrm{p}<0.01$ ), the $\mathrm{RV}$ systolic pressure decreased (from $95 \pm 29 \mathrm{~mm} \mathrm{Hg}$ to $59 \pm 14 \mathrm{~mm}$ $\mathrm{Hg}, \mathrm{p}<0.01$ ) and RV end-diastolic pressure decreased (from $10 \pm 3 \mathrm{~mm} \mathrm{Hg}$ to $8 \pm 3 \mathrm{~mm} \mathrm{Hg}, \mathrm{p}<0.05$ ). Pulmonary valve area increased (from $0.39 \pm 0.11 \mathrm{~cm}^{2} / \mathrm{m}^{2}$ to $0.58 \pm 0.21 \mathrm{~cm}^{2} / \mathrm{m}^{2}, \mathrm{p}<0.01$ ). At 15 or more minutes after valvuloplasty, no significant differences were observed in heart rate, arterial pressure or pulmonary blood flow (Table I).

Follow-up hemodynamic evaluation: At 1-year follow-up hemodynamic evaluation, a further decrease in RV outflow tract gradient and RV systolic pressure occurred in 6 of 7 patients when compared with values obtained immediately after balloon valvuloplasty (Tables I and II, Fig. 1). In addition, pulmonary valve area increased from values immediately after valvulo-

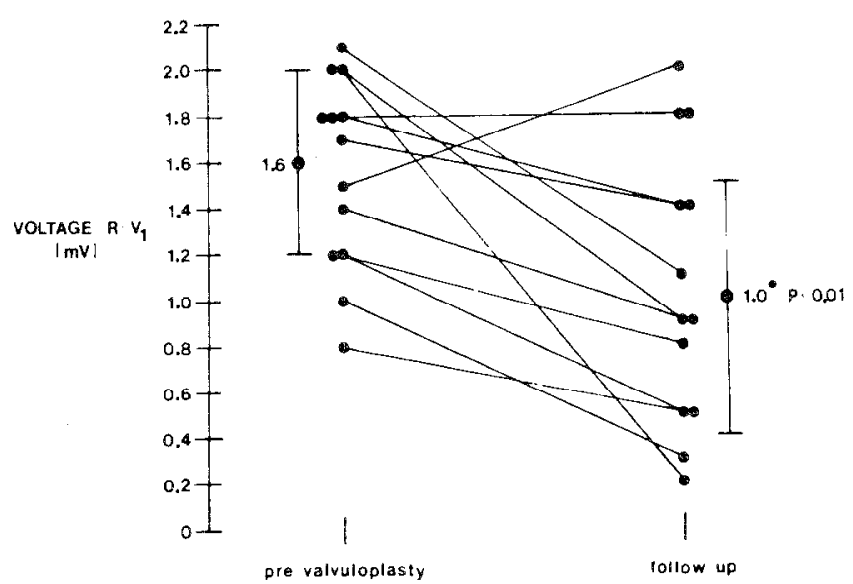

FIGURE 2. Height of $R$ wave in lead $V_{1}\left(R-V_{1}\right)$ in 13 patients reevaluated by standard 12-lead electrocardiogram $16 \pm 9$ months after balloon pulmonary valvuloplasty. Results are mean \pm standard deviation. plasty (from $0.50 \pm 0.18 \mathrm{~cm}^{2} / \mathrm{m}^{2}$ to $0.76 \pm 0.29 \mathrm{~cm}^{2} / \mathrm{m}^{2}$, $\mathrm{p}<0.05$ ).

In patient 1 , an increase in $\mathrm{RV}$ pressure (from $54 / 8$ $\mathrm{mm} \mathrm{Hg}$ to $80 / 10 \mathrm{~mm} \mathrm{Hg}$ ) and $\mathrm{RV}$ outflow tract gradient (from $33 \mathrm{~mm} \mathrm{Hg}$ to $52 \mathrm{~mm} \mathrm{Hg}$ ) occurred at reevaluation of 9 months after the initial valvuloplasty (Tables I and II). Valvuloplasty was repeated using a larger angio-
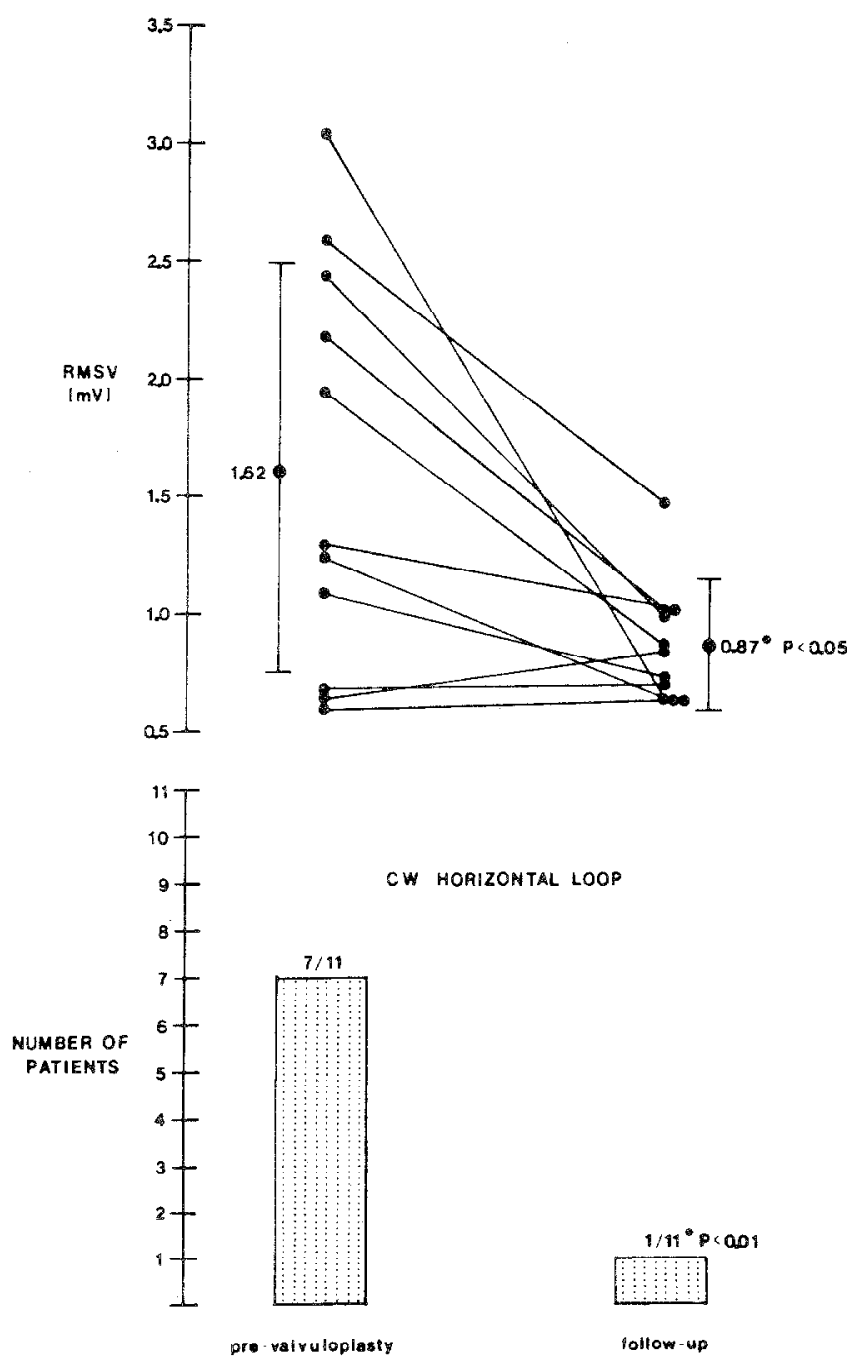

FIGURE 3. Right maximal spatial voltage (RMSV) and number of patients with clockwise (CW) transverse loop in 11 patients reevaluated $13+$ 7 months after balloon pulmonary valvuloplasty with a Frank lead vectorcardiogram. Results are mean \pm standard deviation. 
plasty catheter, which decreased RV pressure (from $80 / 10 \mathrm{~mm} \mathrm{Hg}$ to $65 / 10 \mathrm{~mm} \mathrm{Hg}$ ) and the RV outflow tract gradient (from $52 \mathrm{~mm} \mathrm{Hg}$ to $34 \mathrm{~mm} \mathrm{Hg}$ ).

Noninvasive follow-up evaluation: Follow-up evaluation ( $16 \pm 9$ months) in 13 patients demonstrated a decrease in the intensity of the systolic murmur in 12 of $13(92 \%)$ patients and the appearance of a diastolic murmur consistent with pulmonary regurgitation in 2 of 13 patients ( $15 \%$ ).

All 19 patients had evidence of RV hypertrophy using electrocardiographic standards with a mean $R$ (or $R^{\prime}$ ) voltage of $1.5 \pm 0.4 \mathrm{mV}$ in lead $\mathrm{V}_{1}$ and a QRS axis of $+120 \pm 44^{\circ}$ before balloon valvuloplasty. At follow-up evaluation (16 \pm 9 months) in 13 patients, a significant decrease in R-wave voltage occurred (from $1.6 \pm 0.4 \mathrm{mV}$ to $1.0 \pm 0.6 \mathrm{mV}, \mathrm{p}<0.01$ ) (Fig. 2) with a change in the QRS axis from $+122 \pm 25^{\circ}$ to $+89 \pm 49^{\circ}$.

Vectorcardiograms were performed in 15 of 19 patients before balloon valvuloplasty with a right maximal spafial voltage of $1.43 \pm 0.80 \mathrm{mV}$ and a clockwise anterior transverse loop in 8 of 15 patients (53\%). Vectorcardiography was repeated in 11 patients $13 \pm 7$ months after valvuloplasty and showed a decrease in the right maximal spatial voltage, from $1.62 \pm 0.87 \mathrm{mV}$ to $0.87 \pm$ $0.25 \mathrm{mV}(\mathrm{p}<0.05)$, and a clockwise anterior transverse loop in 1 of 11 patients (9\%) (Fig. 3). A sequence of vectorcardiograms is shown in Figure 4.

Doppler echocardiographic evaluation: Patients $10,11,13,14,15$ and 16 underwent Doppler examination during hemodynamic measurements at cardiac catheterization before and immediately after valvuloplasty. Because no significant differences were observed between the peak-to-peak or peak instantaneous RV outflow tract gradients, only the peak-to-peak RV outflow tract gradients measured at cardiac catheterization and the simultaneous Doppler results were used for data analysis. The regression line and equation depicted in Figure 5 demonstrate excellent correlation $(r=0.99, p<0.001)$.

Because the Doppler-predicted RV outflow tract gradients compared so closely with the hemodynamic measurements, 11 patients underwent Doppler examination $15 \pm 9$ months after valvuloplasty. The RV outflow tract gradient was $86 \pm 29 \mathrm{~mm} \mathrm{Hg}$ before and $38 \pm 9 \mathrm{~mm} \mathrm{Hg}$ immediately after valvuloplasty at cardiac catheterization in these 11 patients. An insignificant decrease in RV outflow tract gradient was seen at follow-up Doppler examination ( $33 \pm 7 \mathrm{~mm} \mathrm{Hg}$, Fig. 6). Follow-up Doppler echocardiograms demonstrated mild pulmonary regurgitation in 8 of 11 patients $(73 \%)$,

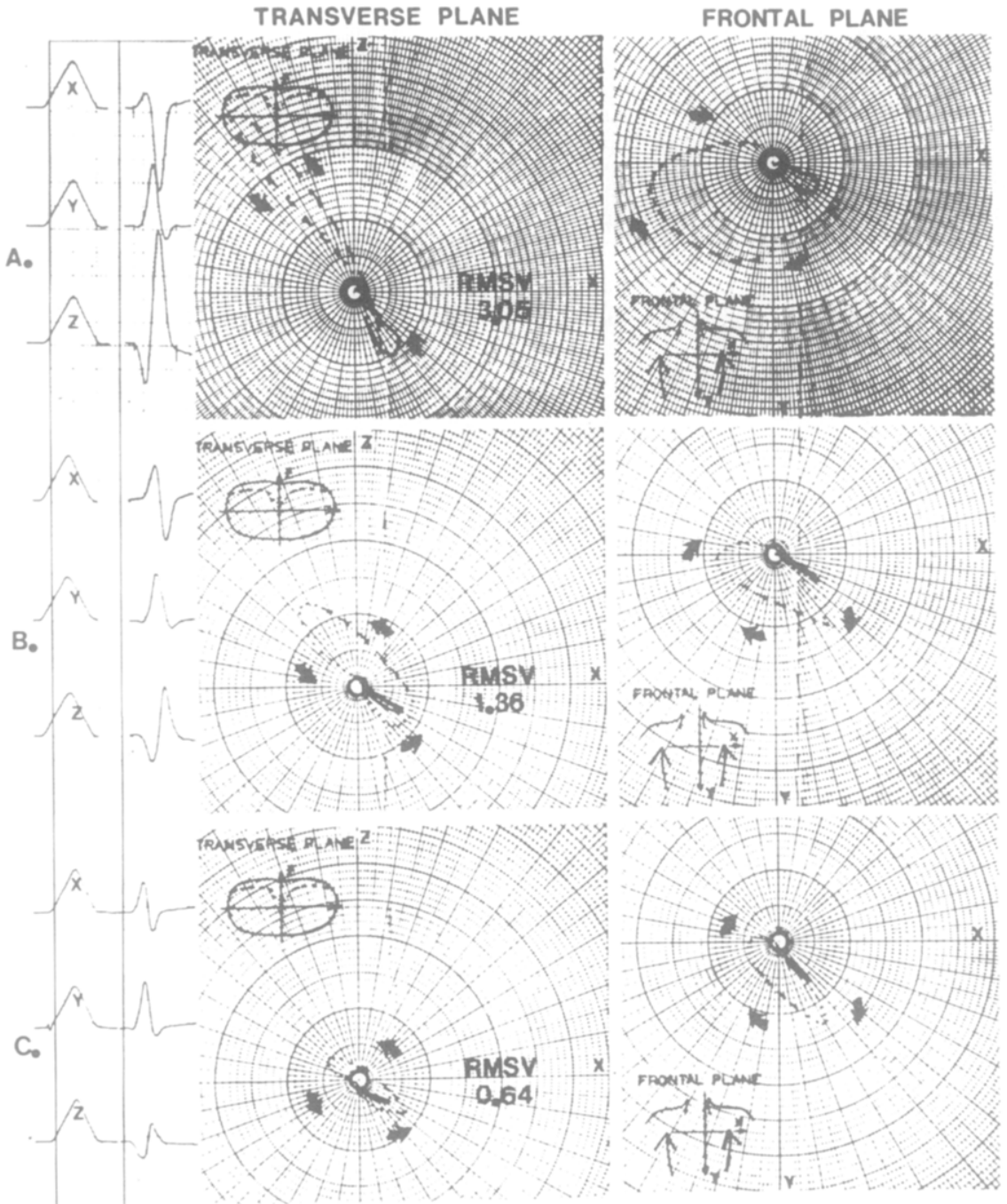

FIGURE 4. Progression of vectorcardiograms in patient 1 using the Frank lead $(X, Y, Z)$ vectorcardiogram. A, before balloon pulmonary valvuloplasty; B, 10 months after balloon pulmonary valvuloplasty; and C, 28 months after balloon pulmonary valvuloplasty. The right maximal spatial voltage (RMSV) is given in millivolts; arrows denote the direction of depolarization. 
whereas only 2 of 11 patients (18\%) had clinical evidence of pulmonary regurgitation.

Complications: All patients had ventricular premature contractions with inflation of the balloon catheter as well as short episodes of bradycardia immediately after balloon deflation. As previously reported, patient 7 experienced a short asymptomatic episode of an accelerated idioventricular rhythm on the 24-hour Holter electrocardiogram. ${ }^{4}$ Subsequently, 12 patients have undergone 24-hour Holter electrocardiography, which has shown only grade I (Lown criteria) ventricular ectopy in 4 patients. After an episode of emesis, recurrent bleeding occurred in patient 1 at the venous site 2 hours after cardiac catheterization; the bleeding responded to direct pressure.

Of the 7 patients who underwent follow-up hemodynamic evaluation, patient 2 had had occlusion of the right femoral and common iliac vein 13 months after her

FIGURE 5. Comparison of simultaneous cardiac catheterization right ventricular outflow tract (RVOT) gradient and Doppler echocardiographically derived RVOT gradient both before and immediately after balloon pulmonary valvuloplasty. Regression equation and $95 \%$ confidence interval are given.

FIGURE 6. Right ventricular outflow tract (RVOT) gradient in 11 patients who underwent Doppler echocardiographic reevaluation 15 \pm 9 months after (post) balIoon pulmonary valvuloplasty. Comparison was made between the RVOT gradient before (pre) balloon pulmonary valvuloplasty and at reevaluation. Data are mean \pm standard deviation.
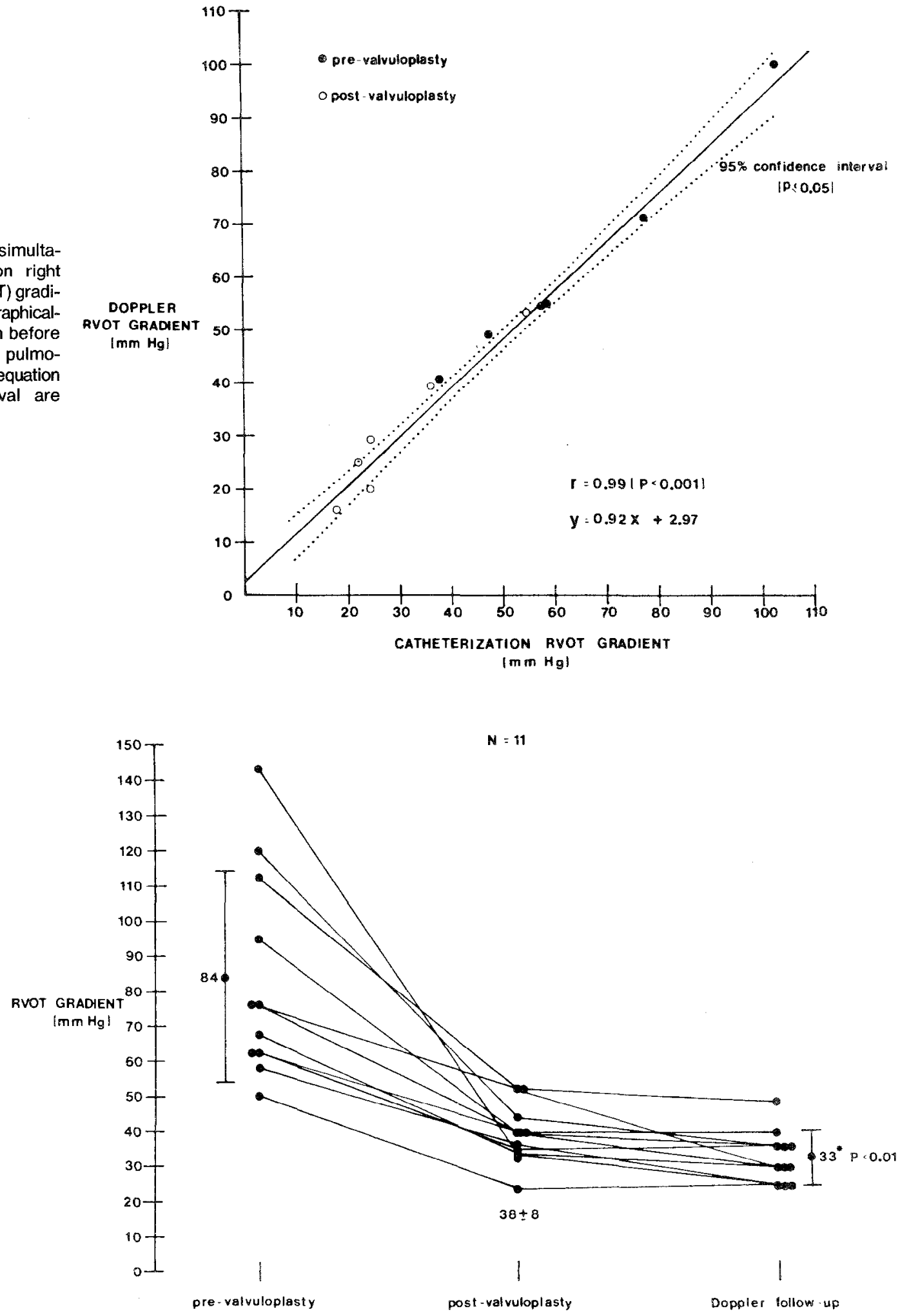
TABLE III Results After Surglcal Intervention for Pulmonary Stenosis

\begin{tabular}{ccc}
\hline & Natural History & \\
Final Pressure & Study & Present Study \\
Gradients $(\mathrm{mm} \mathrm{Hg})$ & $(\mathrm{n}=234)$ & $19)$ \\
\hline$<25$ & $188(80 \%)$ & $2(10 \%)$ \\
$25-49$ & $36(16 \%)$ & $14(74 \%)$ \\
$>50$ & $10(4 \%)$ & $3(16 \%)$ \\
\hline
\end{tabular}

initial evaluation at age 2 years. This was probably related to the balloon valvuloplasty procedure, in view of the large size (No. $9.0 \mathrm{Fr}$ ) of the catheter.

\section{Discussion}

Transluminal balloon valvuloplasty is a safe and effective treatment for moderate to severe PS. Several investigations have demonstrated the acute hemodynamic changes associated with this method of treatment. ${ }^{1-6}$ The results reported are in agreement with those of Kan et $\mathrm{al}^{6,7}$ and support the fact that the relief of the RV outflow tract obstruction is long-lasting. In the 7 patients who underwent hemodynamic evaluation 1 year after valvuloplasty, there was a small continued decrease in RV systolic pressure as well as RV outflow tract gradient. In addition, the first 13 patients have undergone evaluation ( $15 \pm 9$ months) either by Doppler examination or by cardiac catheterization (patients 3 and 4). The RV outflow tract gradient continued to decrease from values obtained immediately after valvuloplasty (from $40 \pm 8 \mathrm{~mm} \mathrm{Hg}$ to $33 \pm 7 \mathrm{~mm} \mathrm{Hg}$ ) in these 13 patients. The results after surgical intervention for PS reported in the natural history study compare favorably with our results (Table III), although there was a tendency for higher RV outflow tract gradients in the balloon valvuloplasty group. ${ }^{9}$

A continued decrease in the RV outflow tract gradient was seen on follow-up evaluation. As previously reported, after balloon valvuloplasty the most striking feature on RV angiography was the severity of dynamic subvalvar obstruction. ${ }^{4}$ This may represent the site of greatest anatomic RV outflow tract obstruction immediately after valvuloplasty and probably regresses with time (as has been shown after surgical valvotomy); regression may explain the continued improvement. ${ }^{10,11}$

In conclusion, these results support the belief that balloon valvuloplasty is effective chronically in the relief of PS and may be considered the treatment of choice. Furthermore, follow-up can now safely be performed without the use of cardiac catheterization by using electrocardiography, vectorcardiography and Doppler echocardiography for the assessment of the severity of residual PS. However, longer follow-up is necessary, and cardiac catheterization should be used in any patient in whom a question arises concerning the severity of the residual $R V$ outflow tract gradient.

\section{References}

1. Kan JS, White RI Jr, Mitchell SE, Gardner TJ. Percutaneous balloon valvuloplasty: a new method for treating congenital pulmonary valve stenosis. N Engl J Med 1982;307:50-542.

2. Pepine CJ, Gessner IH, Feldman RL. Percutaneous balloon valvuloplasty for pulmonic valve stenosis in the adult. Am J Cardiol 1982;50:14421445.

3. Lababidi Z, Wu J. Percutaneous balloon valvuloplasty. Am J Cardiol 1983;52:560-562.

4. Rocchinl AP, Kveselis DA, Crowley D, Dick M, Rosenthal A. Percutaneous balloon valvuloplasty for treatment of congenital pulmonary valvular stenosis in children. JACC $1984 ; 3: 1005-1012$

5. Brodsky SJ. Percutaneous balloon angloplasty: treatment for congenital coarctation of the aorta and congenital valval pulmonary stenosis. Am J Dis Child 1984;138:85t-854.

6. Kan JS, White RI Jr, Mitchell SE, Anderson JH, Gardner TJ. Percutaneous transluminal balloon valvuloplasty for pulmonary valve stenosis. Circulation 1984:69:554-560.

7. Kan JS, White RI Jr, Mitchell SE, Anderson JH. Transluminal balloon valvuloplasty for the treatment of pulmonary and aortic valvular stenosis. Semin vuloplasty for the treatment of
int Radiol 1984;1:217-223.

8. Hatle L, Anglesen B. Doppler ultrasound in Cardiology. Philadelphia: Lea \& Febiger, 1968:8-73.

9. Nugent EW, Freedom RM, Nora JJ, Ellison RC, Rowe RD, Nadas AS. Clinical course in pulmonary stenosis. Circulation 1977;56:suppl I:I-381-47.

10. Engel MA, Holswade GR, Goldberg HP, Lukas DS, Glenn F. Regression after open valvulotomy of infundibular stenosis accompanying severe valvular pulmonary stenosis. Circulation 1958;17:862-873.

11. Griffith BP, Hardesty RL, Siewers RD, Lerberg DB, Ferson PF, Bahnson HT. Pulmonary valvotomy alone for pulmonary stenosis: results in children with and without muscular infundibular hypertrophy. J Thorac Cardiovasc Surg 1982;83:577-583. 